\title{
Dynamic Analysis and Human Comfort Evaluation of Soccer Stadium Grandstands
}

\author{
D.F. Campista**, J.G. Santos da Silva*, A.C.C. Fontenla Sieira*, R.B. Burgos* \\ *(Structural Engineering Department. State University of Rio de Janeiro. Rio de Janeiro/RJ, Brazil) \\ **(Civil Engineering Post-graduate Programme. State University of Rio de Janeiro, Rio de Janeiro/RJ, Brazil)
}

\begin{abstract}
Over the years, many soccer stadiums in Brazil have been designed to withstand accidental loads (people loads) to be of static type. However, based on the changes in the people's behaviour, especially in soccer matches, through the action of groups of fans and also with the use of these structures for rock concerts, these structural systems have been subjected to dynamic impacts related to the dynamic nature of the applied loads. Therefore, some of these stadiums in Brazil have presented excessive vibration problems and have required an effective consideration of the dynamic loadings in the structural design. This way, this research work aims to study the dynamic structural behaviour and evaluate the structural system performance of the Brasilia National Stadium grandstands, when the human comfort is considered. The results achieved during the development of this study are compared with those provided by design standards and international recommendations. The presented results show the relevance of the dynamic analysis on the structural design of soccer stadiums, with respect to obtaining relevant data for human comfort and as well safety of users of this type of structure.
\end{abstract}

Keywords: Grandstands, Soccer stadiums, Human rhythmic actions, Excessive vibrations, Human comfort.

\section{INTRODUCTION}

Structural engineering has been asked to create new design solutions based on the use of slender and flexible systems, contributing to the reduction of the natural frequencies values of these structural models, which can generate structures more susceptible to dynamic loads, as these frequency values may be getting closer to the excitation frequencies. This fact is essential to check the dynamic behaviour of the structural systems, beyond the description of the dynamic loads acting on them. These dynamic loads can produce excessive levels of vibration, which may cause human discomfort and endanger the security of the structure [1-3]. This way, one of the challenges of structural engineering concerns the choice of structural models that better represent your real physical behaviour.

On the other hand, vibrations induced by human rhythmic activities like walking, running, jumping or aerobics consist on a very complex problem. The dynamic excitation characteristics generated during these activities are directly related to the individual body adversities and to the specific way in which each human being executes a certain rhythmic task. All these aspects do not contribute for an easy mathematical or physical characterization of this phenomenon. The analysis of the structural vibrations should include a dynamic analysis and a comparison of the predicted accelerations to the human allowances related to comfort, although simplified criteria may often be used based on the floor flexibility or the natural frequency.

Having these thoughts in mind, the main objective of this research is the study of the dynamic structural behaviour of the Brasilia National Stadium grandstands when subjected to rhythmic human dynamic actions induced by soccer fans. This study will be backed by the use of two different mathematical models, representative of the dynamic loadings, developed based on extensive experimental campaigns [2-4].

Throughout this research work, a numerical analysis is carried out, in order to determine the natural frequencies and the vibration modes of the investigated structural system, to characterize the dynamic behaviour of the grandstands. After that, the dynamic structural response of the system is investigated, contemplating a critical analysis of the maximum acceleration values (peak accelerations), RMS accelerations and vibration dose values (VDV). This way, the studied grandstands dynamic structural response, obtained by numerical simulations, is compared to the limiting values proposed by several authors and design codes [4-9].

By checking the results achieved in this research, can be presented to the design engineers and builders the high importance that the study of vibrations has the design of the structural system, since high values of accelerations found in this research may represent a clue that the design criteria used currently deserve to be studied in detail and reviewed. 


\section{HUMAN RHYTHMIC ACTIVITIES}

The representation of the mathematical functions related to the modelling of the human rhythmic dynamic loading is described two different experimental and analytical approaches such as proposed by Faisca [2] (dynamic loading model I) and Ellis and Ji [3] apud SCI [4] (dynamic loading model II).
This way, the investigated dynamic loading model I was developed based on an extensive series of experimental tests, in order to simulate the human rhythmic activities (jumping, aerobics and rock concert) and the traditional Hanning function was used to describe mathematically this dynamic loading, as presented in Equation (1).

$$
\begin{gathered}
F(t)=C D\left\{K_{p} P\left[0.5-0.5 \cos \left(\frac{2 \pi}{T_{c}} t\right)\right]\right\} \\
F(t)=0
\end{gathered}
$$

Where:

$\mathrm{F}(\mathrm{t})$ : dynamic loading function $(\mathrm{N})$;

t: time (s);

$\mathrm{T}$ : activity period (s);

$\mathrm{T}_{\mathrm{c}}$ : activity contact period ( $\left.\mathrm{s}\right)$;

$\mathrm{P}$ : person's weight $(\mathrm{N})$;

$\mathrm{K}_{\mathrm{p}}$ : impact coefficient;

$\mathrm{CD}$ : phase coefficient.

It is noteworthy that the impact coefficient $\left(\mathrm{K}_{\mathrm{p}}\right)$ is a load increase coefficient, which considers the impact of the jump on the structure. While the $\mathrm{CD}$ parameter is a weighting of dynamic actions defined according to the activity performed and the number of people acting on the structure.

$$
\begin{gathered}
t \leq T_{c} \\
T_{c} \leq t \leq T
\end{gathered}
$$

This coefficient CD takes into account the effects of the crowd on the structure, which is the degree of synchronism between people acting on the system. Thus, the definition of this parameter takes account of possible variations of lags and rhythm that would reduce the intensity of the load.

Table 1 shows the values of the parameters obtained experimentally by Faisca [2] to represent jumping, aerobics and rock concert. Figure 1 represents a CD parameter graph (lag coefficient) for three activities studied by Faisca [2] extrapolated to a large number of people. The CD coefficient allows the dynamic loads can be used to represent crowds.

Table 1. Human rhythmic activity representation [2].

\begin{tabular}{|c|c|c|c|}
\hline Human Activity & $\mathrm{T}(\mathrm{s})$ & $\mathrm{T}_{\mathrm{c}}(\mathrm{s})$ & $\mathrm{K}_{\mathrm{p}}$ \\
\hline Free Jumps & $0.44 \pm 0.15$ & $0.32 \pm 0.09$ & $3.17 \pm 0.58$ \\
\hline Aerobics & $0.44 \pm 0.09$ & $0.34 \pm 0.09$ & $2.78 \pm 0.60$ \\
\hline Rock concert & $0.37 \pm 0.03$ & $0.33 \pm 0.09$ & $2.41 \pm 0.51$ \\
\hline
\end{tabular}

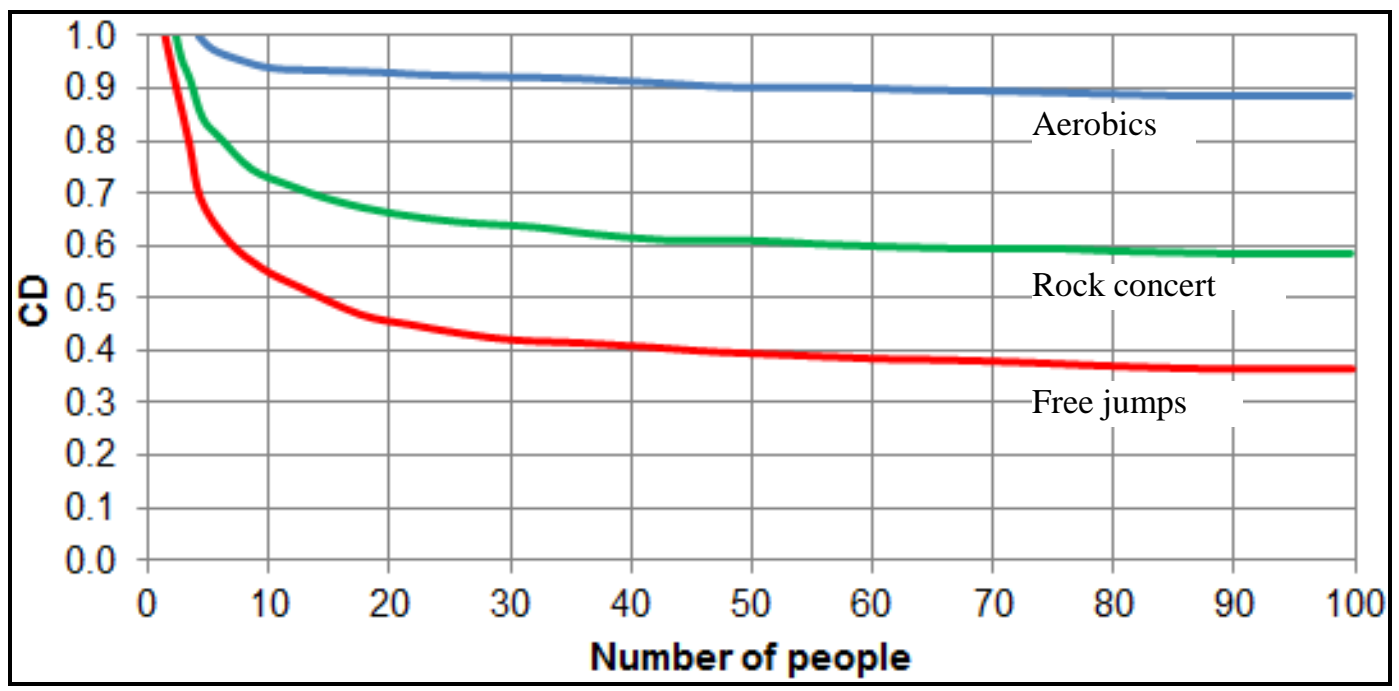

Figure 1. Phase coefficients [2]. 
The dynamic loading model II was developed taking into account the crowd load existing on structures during the practice of human rhythmic activities. According to Ellis and Ji [3] apud SCI [4], for the definition of that crowd load, some factors must be taken into account, including the density of the crowd, the area occupied by the crowd, the frequency range of rhythmic activity practiced, the dynamic effect the crowd and the man-structure interaction. The technical guide entitled "Design of Floors for Vibration: A New
Approach" [4], which was published by SCI (The Steel Construction Institute) presents this loading model proposed by Ellis and Ji [3].

For the determination of the mathematical function representative of the dynamic loading produced by human rhythmic activities experimental tests with different groups of up to sixty-four people were developed, in order to determine the values of the Fourier coefficients of the mathematical function, as presented in Equations (2) to (5).

$$
\begin{gathered}
F(t)=G\left\{1+\sum_{n=1}^{\infty} r_{n, v} \sin \left(2 n \pi f_{p} t+\phi_{n}\right)\right\} \\
r_{1, v}=1.61 v^{-0.082} \\
r_{2, v}=0.94 v^{-0.24} \\
r_{3, v}=0.44 v^{-0.31}
\end{gathered}
$$

Where:

$\mathrm{F}(\mathrm{t})$ : dynamic loading function $(\mathrm{N})$;

$\mathrm{t}$ : time (s);

$f_{p}$ : frequency of the jumping load $(\mathrm{Hz})$;

$\mathrm{v}$ : number of persons;

$\mathrm{r}_{\mathrm{n}, \mathrm{v}}$ : Fourier coefficient of the $\mathrm{n}^{\text {th }}$ term;

$\mathrm{G}$ : person's weight $(\mathrm{N})$; $\phi_{n}$, phase lag of the $\mathrm{n}^{\text {th }}$ term.

Considering only one person practising the rhythmic activity, the Fourier coefficient $\left(r_{n, v}\right)$ can be used according to Table 2. Figure 2 shows a comparison among the investigated dynamic loading functions in frequency domain.

Table 2. Fourier coefficient and phase lag angles [4].

\begin{tabular}{|c|c|c|c|c|c|c|c|}
\hline \multicolumn{2}{|c|}{ Human Activity } & \multicolumn{7}{|c|}{$\mathrm{N}$} \\
\cline { 3 - 8 } & 1 & 2 & 3 & 4 & 5 & 6 \\
\hline \multirow{2}{*}{ Low aerobics } & $\mathrm{r}_{\mathrm{n}}$ & $9 / 7$ & $9 / 55$ & $2 / 15$ & $9 / 247$ & $9 / 391$ & $2 / 63$ \\
\cline { 2 - 8 } & $\phi_{\mathrm{n}}$ & $-\pi / 6$ & $-5 \pi / 6$ & $-\pi / 2$ & $-\pi / 6$ & $-5 \pi / 6$ & $-\pi / 2$ \\
\hline \multirow{2}{*}{ High aerobics } & $\mathrm{r}_{\mathrm{n}}$ & $\pi / 2$ & $2 / 3$ & 0 & $2 / 15$ & 0 & $2 / 35$ \\
\cline { 2 - 8 } & $\phi_{\mathrm{n}}$ & 0 & $-\pi / 2$ & 0 & $-\pi / 2$ & 0 & $-\pi / 2$ \\
\hline \multirow{2}{*}{ Normal jumping } & $\mathrm{r}_{\mathrm{n}}$ & $9 / 5$ & $9 / 7$ & $2 / 3$ & $9 / 55$ & $9 / 91$ & $2 / 15$ \\
\cline { 2 - 8 } & $\phi_{\mathrm{n}}$ & $\pi / 6$ & $-\pi / 6$ & $\pi / 2$ & $-5 \pi / 6$ & $-\pi / 6$ & $-\pi / 2$ \\
\hline
\end{tabular}

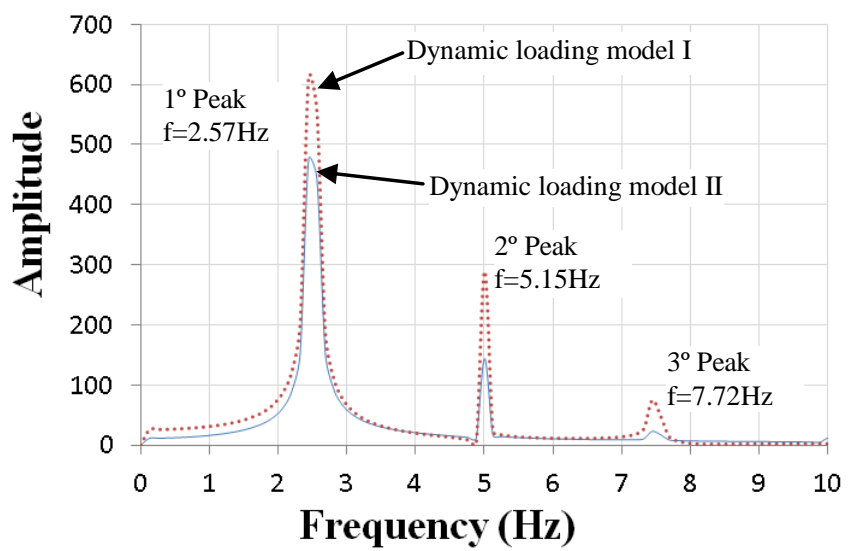

Figure 2. Dynamic loading induced by twisted. 


\section{STRUCTURAL MODEL}

In this work, the investigated structural model corresponds to the Brasilia National Stadium grandstands, composed of slabs, beams, columns and concrete stairs. The grandstands, which have the capacity to hold 71.400 people [10], are divided into three different levels: upper, middle and lower. In this structural model, the grandstands present four types of different sectors. The selected structural sector to be studied in this analysis was $4 \mathrm{G}$ sector, since this sector presents an intermediate width and represents the average behaviour between the different sectors of the stadium [10].
The total height of the grandstands (upper, middle and lower) is equal to $50.59 \mathrm{~m}$ and its structural system presents more than 288 columns, with height of $36 \mathrm{~m}$. The shortest distance between the grandstand seats and the soccer field is equal to $7.5 \mathrm{~m}$ and the field dimensions are equal to $105 \mathrm{~m} \mathrm{x}$ $68 \mathrm{~m}$. Figure 3 shows a typical top view of the structural model with the $4 \mathrm{G}$ sector highlighted and Figure 4 illustrates a radial structural section of the investigated grandstands. Regarding the physical characteristics of the materials used in the structural model, the concrete has longitudinal secant modulus $\left(\mathrm{E}_{\mathrm{cs}}\right)$ equal to 30GPa, Poisson's ratio (v) of 0.2 and density $\left(\gamma_{c}\right)$ equal to $25 \mathrm{kN} / \mathrm{m}^{3}$.

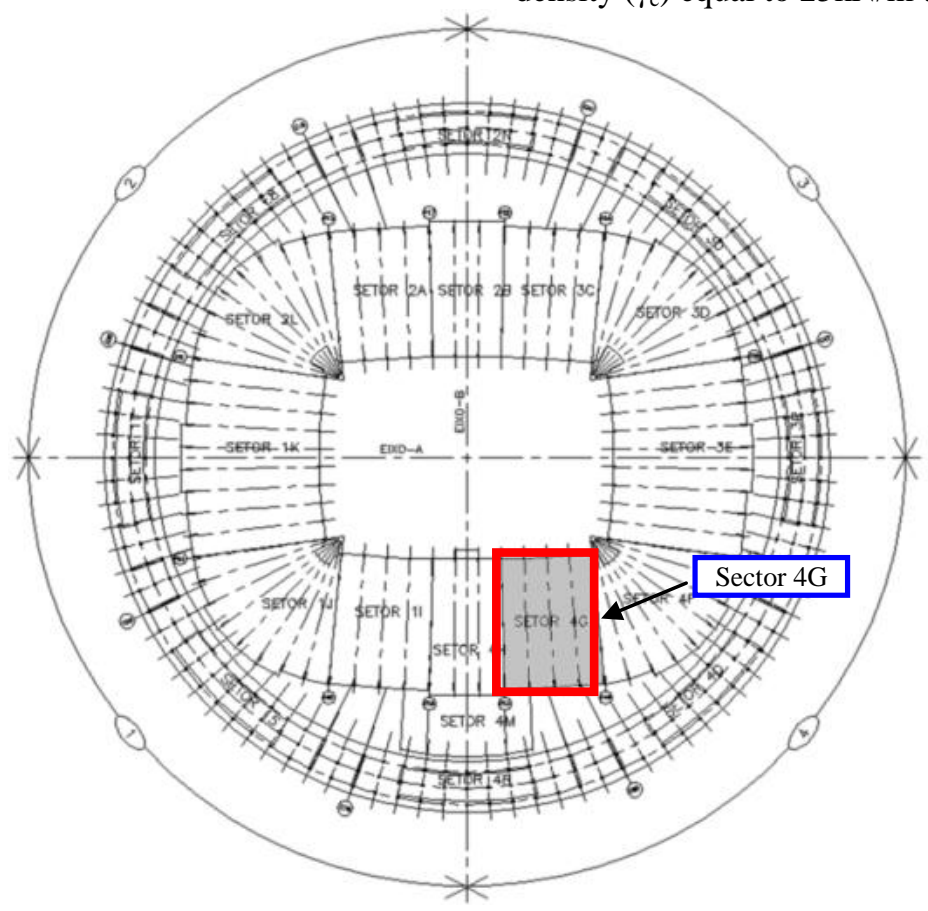

Figure 3. Top view of the stadium [10].

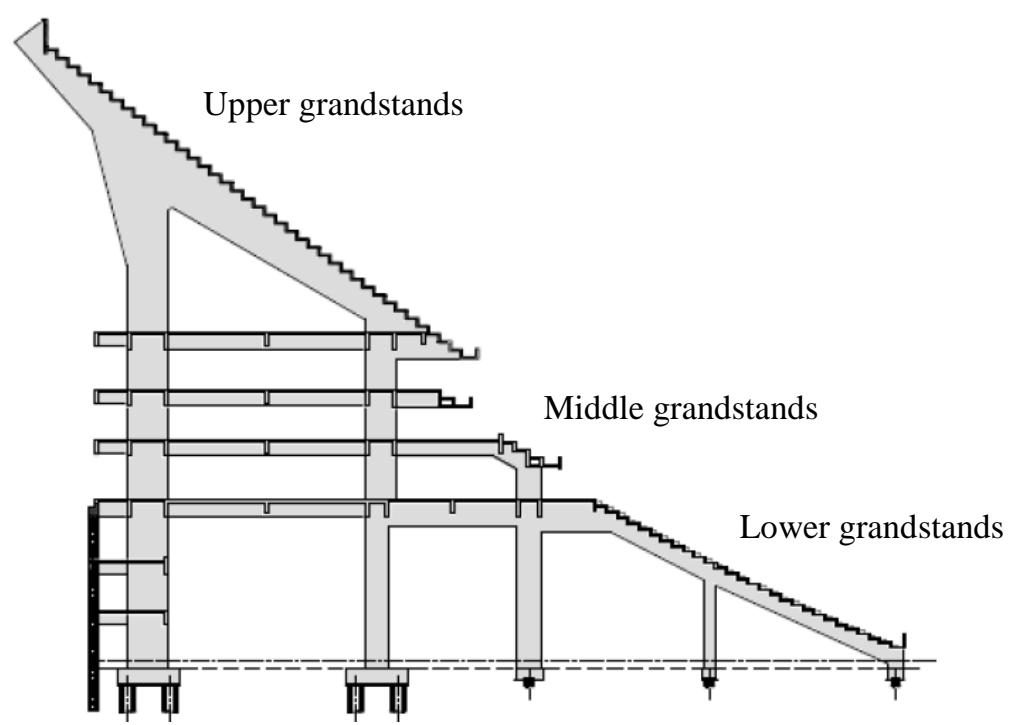

Figure 4. Structural section [10]. 
The numerical model was developed using the ANSYS program [11], based on finite element simulations. The finite element SHELL63 was used to represent the three-dimensional frames, the concrete slabs and the footstep. On the other hand, to simulate the internal beams of the system the threedimensional element BEAM44 was used. Figure 5 presents the finite element model developed to represent the grandstands, based on the use of ANSYS program [11].

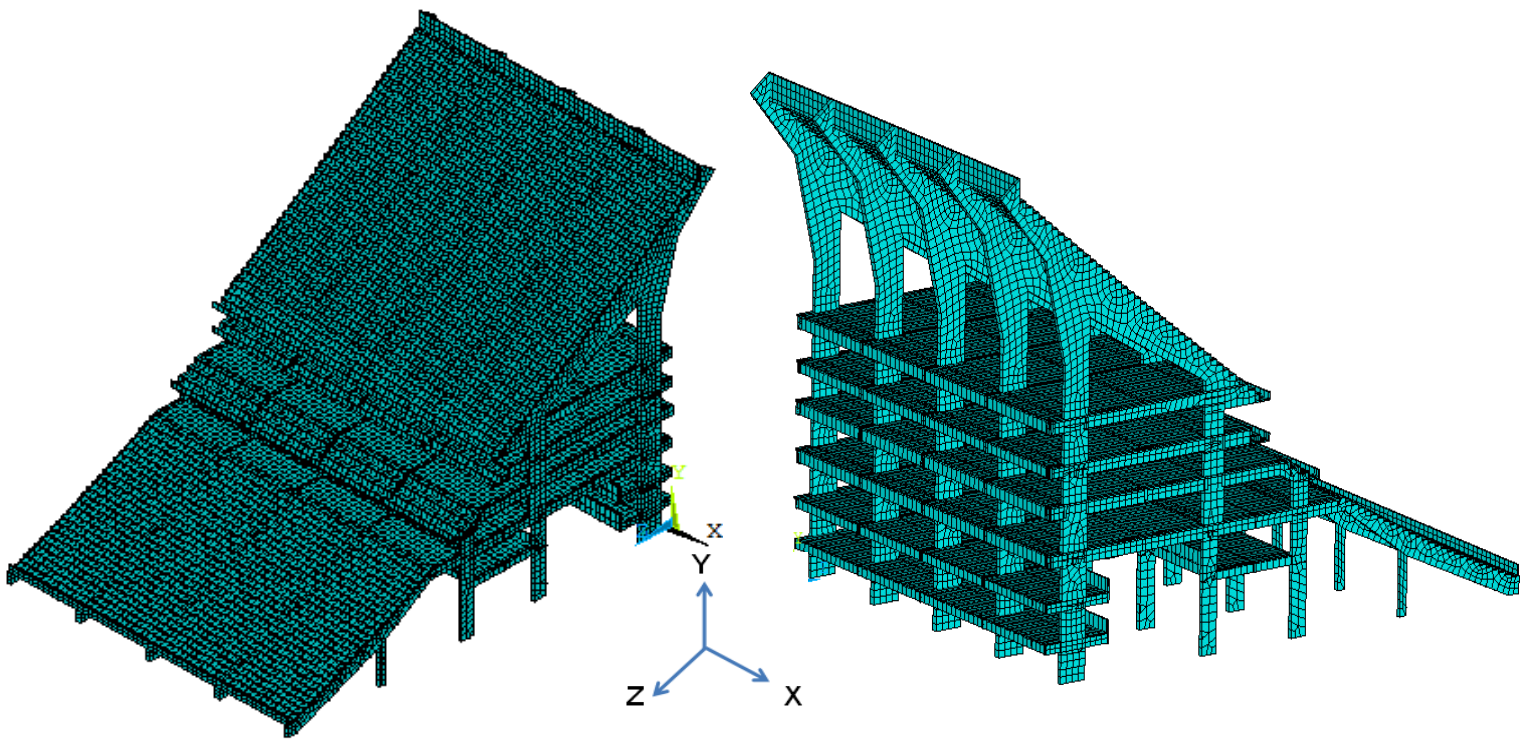

Figure 5. Finite element model of the grandstands.

\section{DYNAMIC ANALYSIS}

Initially, the modal analysis was carried out and it was verified the first fourteen natural frequencies of the analysed grandstands are in the range of $0.96 \mathrm{~Hz}$ to $7.60 \mathrm{~Hz}$. In order to analyse the dynamic structural response of the system it was adopted an excitation frequency of $2.50 \mathrm{~Hz}$ ( $\mathrm{f}=$ $2.50 \mathrm{~Hz}$ ), considered as a characteristic frequency of the dynamic loading induced by soccer fans [10].
This frequency value $(\mathrm{f}=2.50 \mathrm{~Hz}$ ) is in resonance with the third vibration mode of the structure, illustrated in Figure 6. In this work, two different situations of dynamic loading have been studied, as presented in in Table 3, simulating the action of the people on the grandstands at a traditional soccer game, with the objective to check the influence of the number of people on the dynamic response of the analysed structural system.

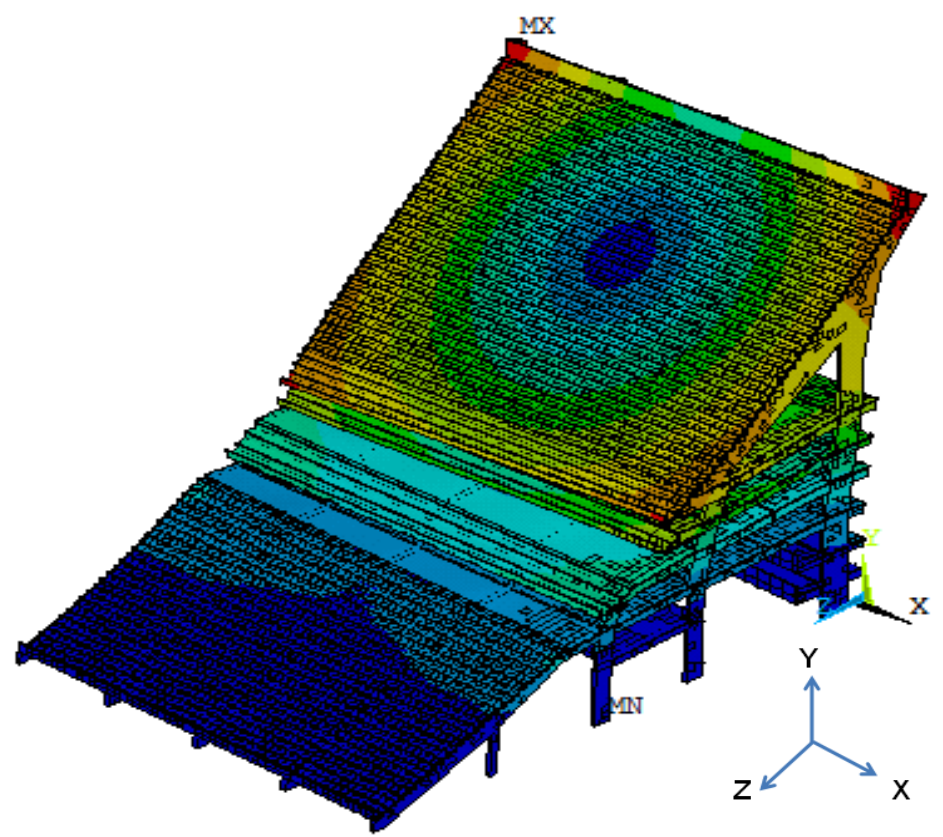

Figure 6. Third vibration mode $\left(\mathrm{f}_{03}=2.45 \mathrm{~Hz}\right)$ : torsion around the vertical axis $\mathrm{X}$. 

ISSN : 2248-9622, Vol. 6, Issue 11, (Part -5) November 2016, pp.23-31

Table 3. Investigated dynamic loading situations.

\begin{tabular}{|c|c|}
\hline Investigated Loading Situations & Dynamic Loads on Grandstands \\
\hline LS-I & $100 \%$ occupancy on the grandstands \\
\hline LS-II & $100 \%$ occupancy on the upper grandstands \\
\hline
\end{tabular}

The dynamic structural response was investigated considering four different points, see Figure 7 . These points were chosen, based on the higher modal amplitudes present in the investigated vibration modes of the grandstands. In Figure 7, point 1 is related to the end of the last footstep of the upper grandstand; point 2 is at the centre of the last footstep of the upper grandstand; point 3 is located in the middle of the first span, between two concrete beams, at the height of the reinforced concrete column and the point 4 is at the end of the first footstep of the upper grandstand, as illustrated in Figure 7.

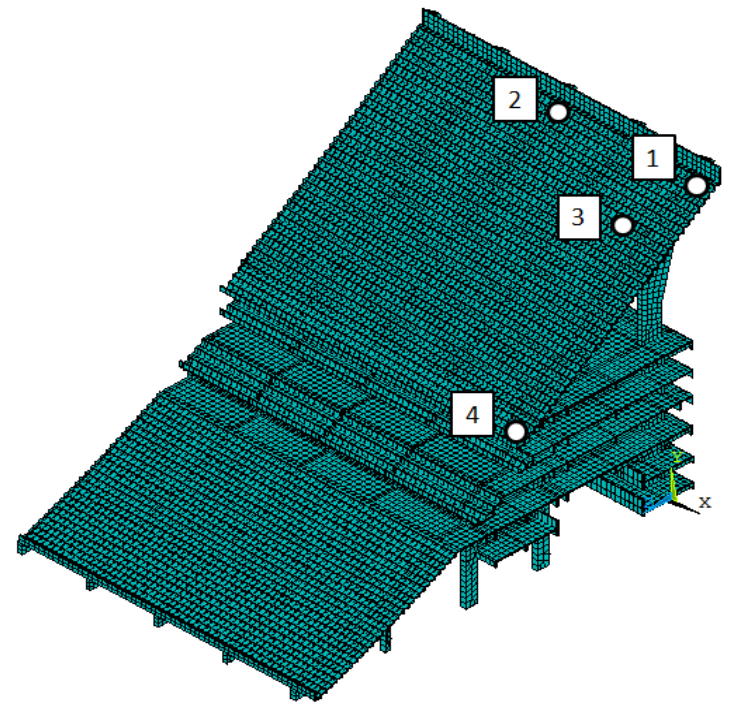

Figure 7. Investigated analysis points on the grandstands.

\section{HUMAN COMFORT ANALYSIS}

In the dynamic analysis, the structural damping was considered equal to $1 \%$, thus being situated in the range of $1 \%$ to $3 \%$, according to ISO 10137 [12] and SCI recommendations [4]. This way, the dynamic response of the grandstands, in time domain, considering the most unfavourable loading situation (LS-I, see Table 3) is presented in Figure 8. It can be noted that the peak accelerations values were equal to $0,36 \mathrm{~m} / \mathrm{s}^{2}$ and $0,62 \mathrm{~m} / \mathrm{s}^{2}$, respectively,

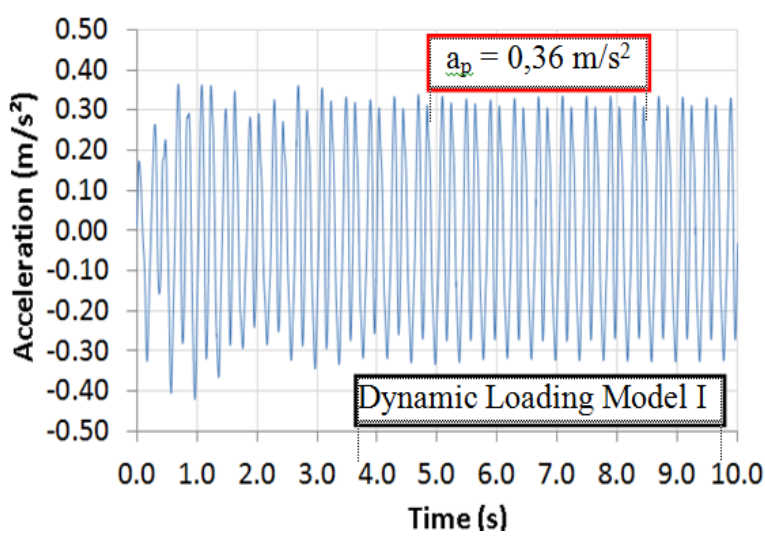

when the dynamic loading models I and II are considered. In sequence of the study, Tables 4 and 5 shows the numerical results obtained considering two dynamic loading situations (see Table 3), based on the use of the dynamic loading model I [2] [see Equation (1)] and dynamic loading model II [3, 4] [see Equations (2) to (5)]. Tables 6 and 7 shows the human comfort acceptance criteria considered in this investigation [4-9], in order to evaluate the human comfort of the investigated structural system.

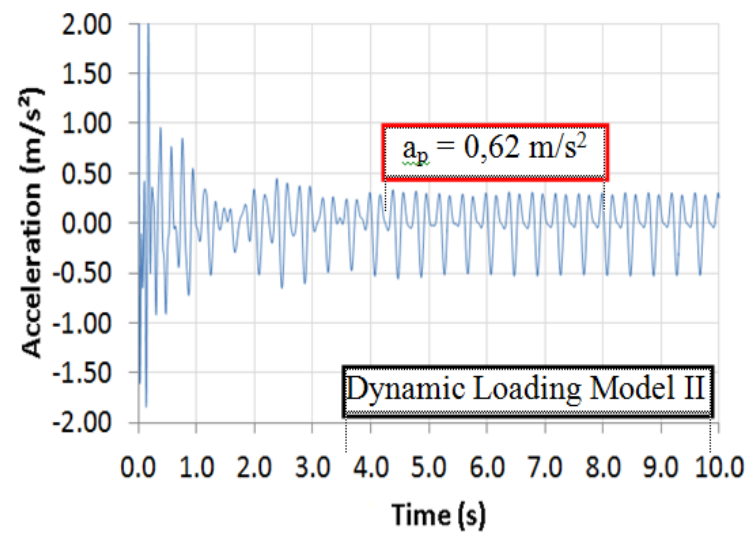

Figure 8. Dynamic structural response of the grandstands in time domain. 
Table 4. Accelerations obtained in LS-I situation.

\begin{tabular}{|c|c|c|c|c|c|c|}
\hline \multirow{3}{*}{ Points } & \multicolumn{3}{|c|}{ Dynamic Loading Model I } & \multicolumn{3}{|c|}{ Dynamic Loading Model II } \\
\hline & \multicolumn{2}{|c|}{ Acceleration $\left(\mathrm{m} / \mathrm{s}^{2}\right)$} & \multirow{2}{*}{$\begin{array}{c}\text { VDV } \\
\left(\mathrm{m} / \mathrm{s}^{1,75}\right)\end{array}$} & \multicolumn{2}{|c|}{ Acceleration $\left(\mathrm{m} / \mathrm{s}^{2}\right)$} & \multirow{2}{*}{$\begin{array}{c}\text { VDV } \\
\left(\mathrm{m} / \mathrm{s}^{1,75}\right)\end{array}$} \\
\hline & $a_{p}$ & $a_{\mathrm{w}, \mathrm{RMS}}$ & & $a_{p}$ & $\mathrm{a}_{\mathrm{w}, \mathrm{RMS}}$ & \\
\hline 1 & 0.16 & 0.10 & 0.20 & 0.25 & 0.15 & 0.38 \\
\hline 2 & 0.21 & 0.13 & 0.27 & 0.33 & 0.18 & 0.47 \\
\hline 3 & 0.36 & 0.23 & 0.44 & 0.62 & 0.30 & 0.77 \\
\hline 4 & 0.21 & 0.12 & 0.25 & 0.24 & 0.18 & 0.48 \\
\hline
\end{tabular}

Table 5. Accelerations obtained in LS-II situation.

\begin{tabular}{|c|c|c|c|c|c|c|}
\hline \multirow{3}{*}{ Points } & \multicolumn{3}{|c|}{ Dynamic Loading Model I } & \multicolumn{3}{|c|}{ Dynamic Loading Model II } \\
\hline & \multicolumn{2}{|c|}{ Acceleration $\left(\mathrm{m} / \mathrm{s}^{2}\right)$} & \multirow{2}{*}{$\begin{array}{c}\text { VDV } \\
\left(\mathrm{m} / \mathrm{s}^{1,75}\right)\end{array}$} & \multicolumn{2}{|c|}{ Acceleration $\left(\mathrm{m} / \mathrm{s}^{2}\right)$} & \multirow{2}{*}{$\begin{array}{c}\text { VDV } \\
\left(\mathrm{m} / \mathrm{s}^{1,75}\right)\end{array}$} \\
\hline & $a_{p}$ & $a_{w, R M S}$ & & $a_{p}$ & $\mathrm{a}_{\mathrm{w}, \mathrm{RMS}}$ & \\
\hline 1 & 0.13 & 0.08 & 0.15 & 0.16 & 0.11 & 0.30 \\
\hline 2 & 0.17 & 0.11 & 0.21 & 0.24 & 0.13 & 0.32 \\
\hline 3 & 0.34 & 0.21 & 0.41 & 0.57 & 0.28 & 0.74 \\
\hline 4 & 0.17 & 0.09 & 0.19 & 0.25 & 0.13 & 0.36 \\
\hline
\end{tabular}


Table 6. Human comfort acceptance criteria: peak accelerations.

\begin{tabular}{|c|c|c|c|}
\hline $\begin{array}{c}\text { Murray et al. } \\
{[5]}\end{array}$ & $\begin{array}{c}\text { Bachmann e } \\
\text { Ammann [6] }\end{array}$ & CEB 209 [7] & \multirow{2}{*}{ People's Reaction } \\
\cline { 1 - 2 } $\mathrm{a}_{\mathrm{p}}\left(\mathrm{m} / \mathrm{s}^{2}\right)$ & $\mathrm{a}_{\mathrm{p}}\left(\mathrm{m} / \mathrm{s}^{2}\right)$ & $\mathrm{a}_{\mathrm{p}}\left(\mathrm{m} / \mathrm{s}^{2}\right)$ & \\
\hline$<0.50$ & $0.50-1.00$ & $<0.55$ & Reasonable limit: passive persons \\
\hline
\end{tabular}

Table 7. Human comfort acceptance criteria: RMS accelerations and VDV values.

\begin{tabular}{|c|c|c|c|}
\hline SCI [4] & $\begin{array}{c}\text { Ellis and Littler } \\
{[8]}\end{array}$ & Setareh [9] & \multirow{2}{*}{ People's Reaction } \\
\hline $\mathrm{a}_{\mathrm{w}, \mathrm{RMS}}\left(\mathrm{m} / \mathrm{s}^{2}\right)$ & VDV $\left(\mathrm{m} / \mathrm{s}^{1.75}\right)$ & VDV $\left(\mathrm{m} / \mathrm{s}^{1.75}\right)$ & \\
\hline$<0.35$ & $<0.66$ & $<0.50$ & Reasonable limit: passive persons \\
\hline $0.35-1.27$ & $0.66-2.38$ & $0.50-3.50$ & Disturbing \\
\hline $1.27-2.47$ & $2.38-4.64$ & $3.50-6.90$ & Unacceptable \\
\hline$>2.47$ & $>4.64$ & $>6.90$ & Probably causing panic \\
\hline
\end{tabular}

Based on the results presented in Tables 4 and 5 , the highest value of peak acceleration has been found in loading situation LS-I (see Table 3), where $100 \%$ of the grandstands are utilised by the soccer fans, based on the use of the dynamic loading model II, proposed by Ellis and Ji [3] apud SCI [4] I). This peak acceleration value was equal to $0.62 \mathrm{~m} / \mathrm{s}^{2}$ (see Table 4).

It can be seen from the numerical results presented in Tables 4 to 5 , when the mathematical formulation proposed by Faisca [2] was used in this study, the obtained peak acceleration values do not exceed the limiting values proposed by the design standards and recommendations [4-9], related to the loading situations analysed in this work (LS-I and LS-II, see Table 3), as presented in Tables 4 and 5.

On the other hand, it should be noted that when the dynamic loading model II, proposed by Ellis and Ji [3] apud SCI [4] was considered in the evaluation of the results, some peak accelerations and VDV values surpassed the limiting values proposed by design standards and recommendations [4-9], as shown in Tables 4 and 5.

Based on the analysis of the peak accelerations values (see Tables 4 and 5) obtained based on the use of dynamic loading model II, in accordance with CEB 209 [7], these accelerations values associated with the loading situations LS-I $\left(a_{p}=0.62 \mathrm{~m} / \mathrm{s}^{2}\right)$ and LS-II $\left(a_{\mathrm{p}}=0.57 \mathrm{~m} / \mathrm{s}^{2}\right)$ are within the range considered intolerable by CEB 209 recommendation [7]. Regarding the limiting values proposed by Murray et al. [5], equal to $0.5 \mathrm{~m} / \mathrm{s}^{2}(5 \%$ g), these peak accelerations values [LS-I: $\mathrm{a}_{\mathrm{p}}=0.62 \mathrm{~m} / \mathrm{s}^{2}$ and LS-II: $\left.\mathrm{a}_{\mathrm{p}}=0.57 \mathrm{~m} / \mathrm{s}^{2}\right]$ values surpassed this limit. On the other hand, considering Bachmann and Ammann [6] recommendations these values are acceptable.

When the RMS accelerations values are considered in the analysis the recommended limits to human comfort are satisfied in both dynamic loading situations (see Tables 4 and 5). Taking into account the limits for the VDV values, the results found in this analysis surpassed the acceptable limits proposed by Setareh [9], which is $0.50 \mathrm{~m} / \mathrm{s}^{2}$, considering the acceleration range related to a disturbing condition. Otherwise, based on limiting value established by Ellis and Littler [8], which is $0.60 \mathrm{~m} / \mathrm{s}^{2}$, in both dynamic loading situations LS-I and LS-II this limit was exceeded, using the acceleration range considered disturbing, as shown in Tables 4 and 5 .

Based on the results presented in Tables 4 to 8 , it must be emphasized that point 3 (see Figure 7 ), in the middle of the first span, between two concrete beams, at the height of the reinforced concrete column is the most critical point of the investigated structural system. Note that this critical point is located in a region of the model where the physical phenomenon of resonance occurs between the interaction of the natural vibration frequencies of the grandstands $\left(\mathrm{f}_{03}=2.45 \mathrm{~Hz} ; \mathrm{f}_{05}=5.09 \mathrm{~Hz}\right.$ and $\mathrm{f}_{13}=7.34 \mathrm{~Hz}$ ) and the harmonic components of the dynamic excitation (soccer fans).

\section{CONCLUSIONS}

This research investigated the dynamic structural behaviour of the grandstands of the National Stadium in Brasilia/DF, Brasil, when subjected to rhythmic human dynamic actions. A computational model, based on the finite element method, was developed using the ANSYS program. This model enabled a complete dynamic evaluation of the investigated grandstands, especially in terms of human comfort and its associated vibration serviceability limit states.

In order to investigate the dynamic structural response of the grandstands it was adopted 
an excitation frequency equal to $2.50 \mathrm{~Hz}$, considered as a characteristic frequency of the dynamic loading induced by soccer fans [10]. It must be emphasized that this frequency value $(\mathrm{f}=2.50 \mathrm{~Hz})$ is very close (resonance situation) of the third vibration mode of the structure $\left(\mathrm{f}_{03}=2.45 \mathrm{~Hz}\right)$.

Based on the worst investigated dynamic loading situation (LS-I situation: 100\% occupancy of the grandstands), the maximum acceleration values equal to $0.36 \mathrm{~m} / \mathrm{s}^{2} ; 0.23 \mathrm{~m} / \mathrm{s}^{2}$ and $0.44 \mathrm{~m} / \mathrm{s}^{1.75}$ for the dynamic loading model I (peak acceleration, RMS and VDV values, respectively), proposed by Faisca [2] and $0.62 \mathrm{~m} / \mathrm{s}^{2} ; 0.30 \mathrm{~m} / \mathrm{s}^{2}$ and $0.77 \mathrm{~m} / \mathrm{s}^{1,75}$ for the dynamic loading model II (peak acceleration, RMS and VDV values, respectively), proposed by Ellis and Ji [3] apud SCI [4].

It must be emphasized that the results found based on the use of the dynamic loading model I [2] do not exceed the limiting values recommended by standards and design recommendations [4-9]. On the other hand, with respect to the results found when the dynamic loading model II was considered, the peak acceleration and VDV values surpassed the human comfort limits established by the design guides [4-9].

Finally, comparing the results provided by the use of both dynamic loading models used in this research, in all loading situations studied, it can be concluded that the dynamic structural response values, obtained considering the dynamic loading model II, proposed by Ellis and Ji [3] apud SCI [4], have always been higher than those determined when the dynamic loading model I, established by Faisca [2], was adopted in the analysis. This fact can be explained because the parameters used in the mathematical formulation proposed by Ellis and $\mathrm{Ji}$ [3] apud SCI [4], in order to define the harmonics of the dynamic excitation, presents a much higher energy transfer on the dynamic response when compared with the dynamic loading model I [2].

\section{ACKNOWLEDGMENTS}

The authors gratefully acknowledge the financial support for this work provided by the Brazilian Science Foundation's CAPES, CNPq and FAPERJ.

\section{REFERENCES}

[1] D.F. Campista, Dynamic analysis and human comfort study in the Brasilia National Stadium Grandstands, MSc Dissertation (In Portuguese), Civil Engineering Post-graduate Programme, PGECIV, State University of Rio de Janeiro, UERJ, Rio de Janeiro/RJ, Brazil, 2015.
[2] R.G. Faísca, Characterization of Dynamic Loads due to Human Activities, PhD Thesis (In Portuguese), Civil Engineering Department, COPPE/UFRJ, Rio de Janeiro/RJ, Brazil, pp. 1-240, 2003.

[3] B.R. Ellis, T. Ji, BRE Digest 426, Response of Structures Subject to Dynamic Crowd Loads, ISBN 186081 1744, 2004.

[4] A.L. Smith, S.J. Hicks, P.J. Devine, Design of floors for vibrations: A new approach. SCI Publication P354, Ascot, 2009.

[5] T.M. Murray, D.E. Allen, E.E Ungar, Floor Vibrations due to Human Activity, Steel Design Guide Series, American Institute of Steel Construction, AISC, Chicago, USA, 2003.

[6] H. Bachmann, W. Ammann, Vibrations in structures induced by man and machines, IABSE Structural Engineering Document 3E, International Association for Bridges and Structural Engineering, ISBN 3-85748052-X., 1987.

[7] CEB-209: Comite Euro-International du Beton, (CEB. Vibration problems in structures. Practical guidelines. Bulletin d'information $\mathrm{N}^{\circ}$ 209), 1991.

[8] B.R. Ellis, J.D. Littler, Response of cantilever grandstands to crowd loads. Part I: Serviceability evaluation. Proceedings of the Institution of Civil Engineers Structures and Buildings 157(SB4): 235241, 2004.

[9] M. Setareh, Evaluation and assessment of vibrations owing to human activity. Proceedings of the Institution of Civil Engineers - Structures and Buildings 165(SB5): 219-231, 2012.

[10] G.V.F. Lima, Dynamic Analysis via Finite Element Method of the Brasilia National Stadium, MSc Dissertation (In Portuguese), Civil Engineering Department, University of Brasilia, UnB, Brasília/DF, Brazil, 2013.

[11] ANSYS Swanson Analysis Systems, Inc., P. O. Box 65, Johnson Road, Houston, PA, 15342-0065. Release 11.0, SP1 UP20070830, ANSYS, Inc. is a UL registered ISO 9001:2000 Company. Products ANSYS Academic Research, Using FLEXIm v10.8.0.7 build 26147, Customer 00489194, 2007.

[12] International Standard Organization. Bases for design of structures - Serviceability of buildings and walkways against vibrations, ISO-10137,2007. 